7. Reprod. Fert. (1975) 43, 23-32

\title{
MOTILITY OF THE OVIDUCT AND UTERUS OF THE COW DURING THE OESTROUS CYCLE
}

\author{
Y. RUCKEBUSCH AND F. BAYARD \\ Laboratoire de Physiologie, Ecole Nationale Vétérinaire, and \\ Laboratoire de Médecine Expérimentale, Université P. Sabatier, Toulouse, France*
}

(Received 10th Fuly 1974)

\begin{abstract}
Summary. Recordings of electrical activity of the oviduct and uterus were obtained during three oestrous cycles in cows fitted with an extracellular multi-electrode assembly. The stages of the cycle were identified by the appearance of the cervico-vaginal secretions and changes in the peripheral plasma level of progesterone were determined by radioimmunoassay.

A gradual transition from local non-propagating electrical activity to propagating electrical activity with increase in the duration of contractions and then of their amplitude occurred $48 \mathrm{hr}$ before the onset of oestrus. The transition coincided with a rapid decrease in progesterone level from 5 to $10 \mathrm{ng} / \mathrm{ml}$ to less than 0.1 to $0.4 \mathrm{ng} / \mathrm{ml}$. This phenomenon was recorded from all uterine electrode sites, but was most marked at the uterotubal junction.

Two days before oestrus, trains of potentials and bursts of activity became progressively grouped, apparently randomly, into prolonged phases in the distal portion of the oviduct and over the entire myometrium. During oestrus, the phases of activity became synchronized at these sites and both their amplitude and frequency reached a maximum. The strength but not the frequency of the phases diminished progressively 3 days after oestrus, followed by relative inactivity. The last remaining zone of activity was the uterotubal junction.

During oestrus, the activities of the oviduct and the uterus were modified by oxytocin and adrenaline, the effect of the former being more marked on the uterus and that of the latter on the oviduct.
\end{abstract}

\section{INTRODUCTION}

The hormonal states during the oestrous cycle in the cow are well documented. They involve a pro-oestrous peak of oestradiol 3 days before oestrus as the progesterone level falls sharply and a peak of oestradiol on the 5th day after oestrus when progesterone reaches its basal level (Glencross, Munro, Senior \& Pope, 1973).

By contrast, little is known about the concomitant patterns of oviducal and uterine motility in cattle. Using a balloon technique, Evans \& Miller (1936)

* Postal address: École Nationale Vétérinaire, 23 chemin des Capelles, F-31076 Toulouse Cédex, France. 
recorded strong uterine contractions during oestrus and for a few days after oestrus; the contractions were very weak during the dioestrous period. During the different stages of the oestrous cycle, Hays \& VanDemark (1953a) found no significant differences in the motility indices, or in the effects produced by oxytocin and adrenaline (Hays \& VanDemark, 1953b).

More recently, using open-tipped catheters, Döcke (1962) demonstrated a clear relationship between the motility pattern of the uterine horn and the phases of the oestrous cycle. He reported a maximal rhythmic activity during oestrus with contractions running from the cervix towards the oviduct and a reversal of their direction at the end of oestrus. Chen, MacDonald \& Hawes (1966) measured intrauterine changes and electrical activity by attaching electrodes to the cervix after insertion by the vaginal route and recorded an increased motility during oestrus which was enhanced by oxytocin.

The possible reaction of the endometrium to the presence of internal measuring devices or its response to their insertion justifies the use of electrodes externally implanted in the wall. Three to four groups of electrodes similar to those commonly used for the small intestine (Ruckebusch, 1970) 'map out' the electrical activity which spreads over the entire surface of the organ. Fixation of the electrodes, which is seemingly achieved by proliferation of the serosa within 3 to 4 days, allows chronic artefact-free recordings of the electrical activity over extended periods, e.g. 3 to 4 months. In addition, this technique permits comparison of records at different stages of oestrus in the same animal which thus acts as its own control (Ruckebusch \& Grivel, 1974). When the level of electrical activity is automatically plotted by means of a two-line integrator circuit (Latour, 1973), quantitative aspects may be assessed.

The experiments were undertaken (i) to analyse the spontaneous motility of the different regions of the oviduct and uterus during the oestrous cycle, (ii) to identify any possible interactions between the activity of the oviduct and the uterus, (iii) to investigate the influence of the hormonal environment on the effect of oxytocin and adrenaline.

\section{MATERIALS AND METHODS}

Four parous cows, two Friesian ( $\mathrm{A}$ and $\mathrm{M}$ ) aged 4 and 5 years and two Brune des Alpes ( $G$ and $U$ ) aged 9 and 15 years, were used in these studies during the winter of 1973. The cows were subjected to laparotomy under general anaesthesia (pentobarbitone sodium, $20 \mathrm{mg} / \mathrm{kg}$ ), a longitudinal incision being made just anterior to the tensor fascia lata on the right side. Three groups of electrodes were positioned on the myometrium, one near the tubal end at $2 \mathrm{~cm}$ (Text-figs 1 and 4) or at $4 \mathrm{~cm}$ (Text-fig. 2) from the uterotubal junction, one mid-way along the corpus uteri and the third at the cervical end. In the same manner, three pairs of electrodes were placed in Cows $C$ and $U$ on the right oviduct, one near the ovary on the ampulla, one at the uterotubal junction, and the last mid-way between these sites. At the same time, bilateral ovariectomy was performed on Cow $U$ and a strain gauge was positioned mid-way along the uterine horn.

Electrical activity was directly recorded on a polygraph at a paper speed of 
$0.5 \mathrm{~mm} / \mathrm{sec}$ for 7 -hr periods each day (10.00 to $17.00 \mathrm{hours})$ and for $24 \mathrm{hr} /$ day by means of a potentiometric recorder (automatically integrated every $30 \mathrm{sec}$; Latour, 1973) at a paper speed of $1 \mathrm{~mm} / \mathrm{min}$. For additional information, uterine pressure was recorded for one complete oestrous cycle by means of a small balloon $(0.5 \mathrm{~cm}$ diam.) introduced through the cervix in Cow $\mathrm{M}$, and from the strain gauge in Cow $\mathrm{U}$. To avoid artefacts due to movement, recumbency was prevented at night in order to induce the animals to lie down during the daytime recording sessions.

Recordings of electrical activity were started 1 week after surgery and continued for 2 months, i.e. during three spontaneous oestrous cycles. These three oestrous cycles were of normal length, averaging 20 to 21 days in Cows $A$ and $\mathrm{M}$ and 22 days in Cow $\mathrm{C}$. Peripheral blood samples were collected daily and the plasma was stored at $-20^{\circ} \mathrm{C}$ and later assayed for oestradiol- $17 \beta$ and progesterone concentrations by a radioimmunoassay using antisera raised in rabbits against oestradiol-17 $\beta-7 \alpha$ butyrate-BSA and progesterone-11-BSA conjugates, $\left[2,4,6,7-{ }^{3} \mathrm{H}\right]$ oestradiol $(100 \mathrm{Ci} / \mathrm{mmol})$ and $\left[1,2,6,7-{ }^{3} \mathrm{H}\right]$ progesterone (100 $\mathrm{Ci} / \mathrm{mmol}$ ) as the tracers, and dextran-coated charcoal for separation of bound and free fractions.

The effect of catecholamines (adrenaline and noradrenaline, $1 \mu \mathrm{g} / \mathrm{kg}$ intravenously) and oxytocin (0.005 i.u./kg intravenously) were examined every 2 nd day in Cows $\mathrm{M}$ and C. An oestrogen, oestradiol benzoate (Folliculine I.S.T.), $25 \mu \mathrm{g} / \mathrm{kg}$, was injected into Cow $U$ at weekly intervals. The effect of mechanical vaginal stimulation during the second and third oestrous cycles on contractile activity was recorded during the same period. This was achieved by inserting a bottle-brush intravaginally to a depth of $20 \mathrm{~cm}$ which also permitted collection of cervical secretions.

\section{RESULTS}

\section{Analysis of electromyograms}

The electrical activity included two main patterns: small groups ('bursts') of potentials of 0.1 to $0.6 \mathrm{mV}$ firing at a frequency of $>1 / \mathrm{sec}$, and more extended periods ('trains') of potentials of higher amplitude $(0.6$ to $1.2 \mathrm{mV})$ firing at a frequency of $<1 / \mathrm{sec}$. When these two patterns are intermingled and occur for prolonged periods (from 1 to $10 \mathrm{~min}$ ), the term 'phases' was employed. Most of the activity occurred for about 1 week during each cycle, i.e. 2 to 3 days before (pro-oestrus), and 2 to 3 days after the day of oestrus (metoestrus). The period of dioestrus will be designated here as the last 2 weeks of the cycle.

Oviduct. During dioestrus, sporadic weak potentials were recorded near the uterotubal junction. Their amplitude and frequency increased progressively during pro-oestrus, forming trains of approximately 30 -sec duration. At oestrus and metoestrus, the activity became continuous and involved the middle portion of the oviduct. The potentials showed different amplitudes, the majority falling into two groups $(0.4$ and $1.2 \mathrm{mV})$, regardless of waxing and waning periods. The polarity of potentials from time to time inverted at the two active sites of the oviduct. The firing rate at these sites differed slightly, being more rapid $(17 / \mathrm{min})$ at the uterotubal junction compared to the middle point 
$(15 / \mathrm{min})$. At times, the difference was more noticeable, the firing rate reaching about $30 / \mathrm{min}$ at the uterotubal junction. The activity of this latter segment was the first to cease at the end of metoestrus. No activity was registered from the ovarian extremity of the oviduct except during metoestrus when isolated potentials occurred (Text-fig. 1).

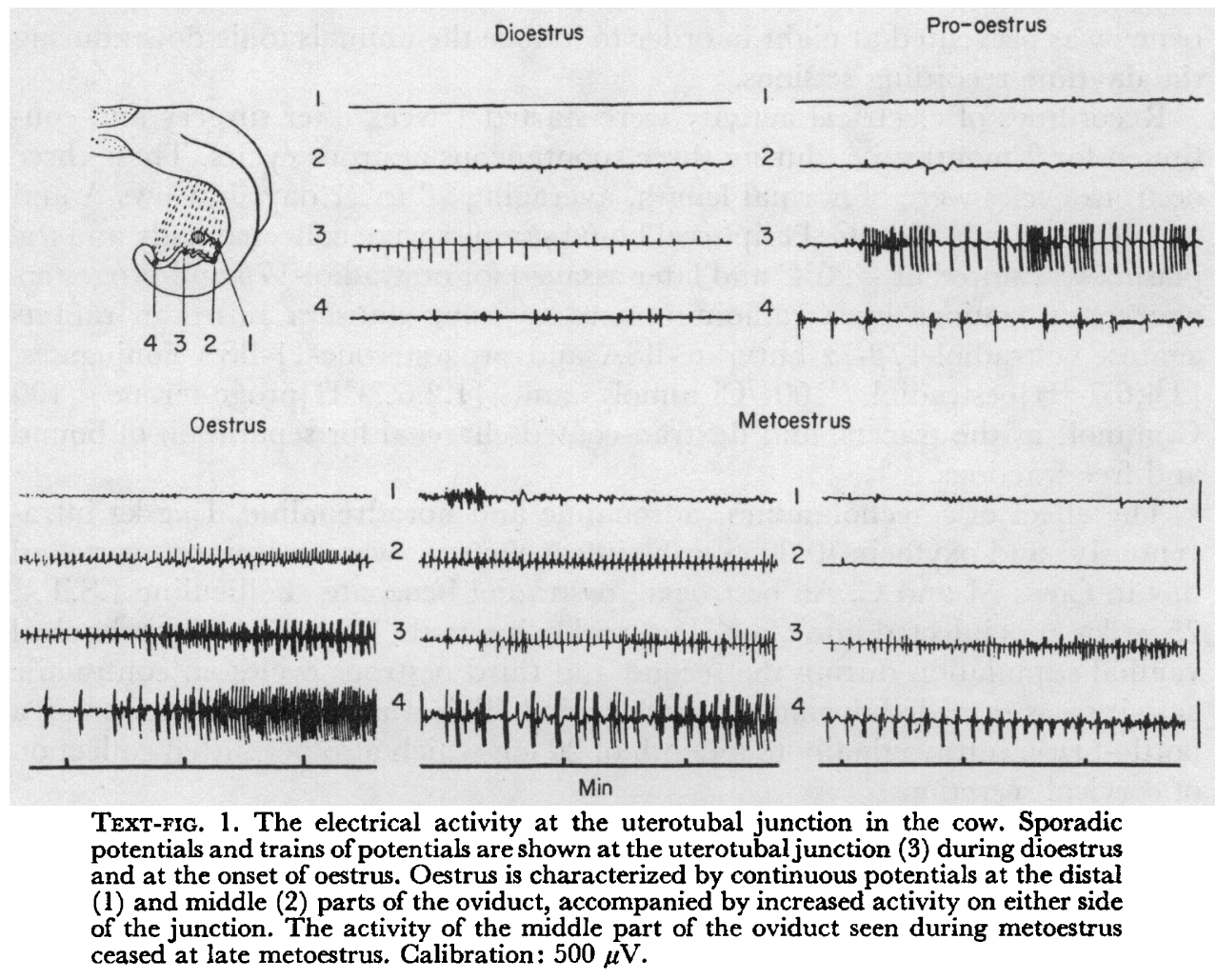

Uterus. During dioestrus, brief, weak, irregular bursts of potentials were recorded from the three sites and isolated high-amplitude potentials occurred randomly at the cervical end. During pro-oestrus, increases in amplitude and frequency were accompanied by a grouping of activity into bursts of 5- to 50-sec duration. Trains of potentials were seen initially at the cervical end and then over the entire organ. At oestrus, the trains were mingled with bursts to form prolonged phases lasting 1 to $7 \mathrm{~min}$ which occurred two or three times every hour. During metoestrus, shorter and more frequent phases of activity were recorded, but their amplitude was reduced (Text-fig. 2). This phenomenon was accompanied by an increase in the viscosity of cervical secretions and a reduction in the response to vaginal stimulation (see below).

Small variations in muscular tone of the body of the uterus were recorded from the strain gauge during the trains of potentials and brief but strong changes occurred during the burst activity. From the balloon inserted through the cervix at approximately the level of the group of electrodes at the cervical end, a progressive increase of the baseline with superimposed small contractions 
were registered during the phases in which trains of potentials predominated (Text-fig. 3a). When bursts were preponderant, the pressure changes followed a different pattern, returning to the baseline between each contraction (Textfig. 3b).

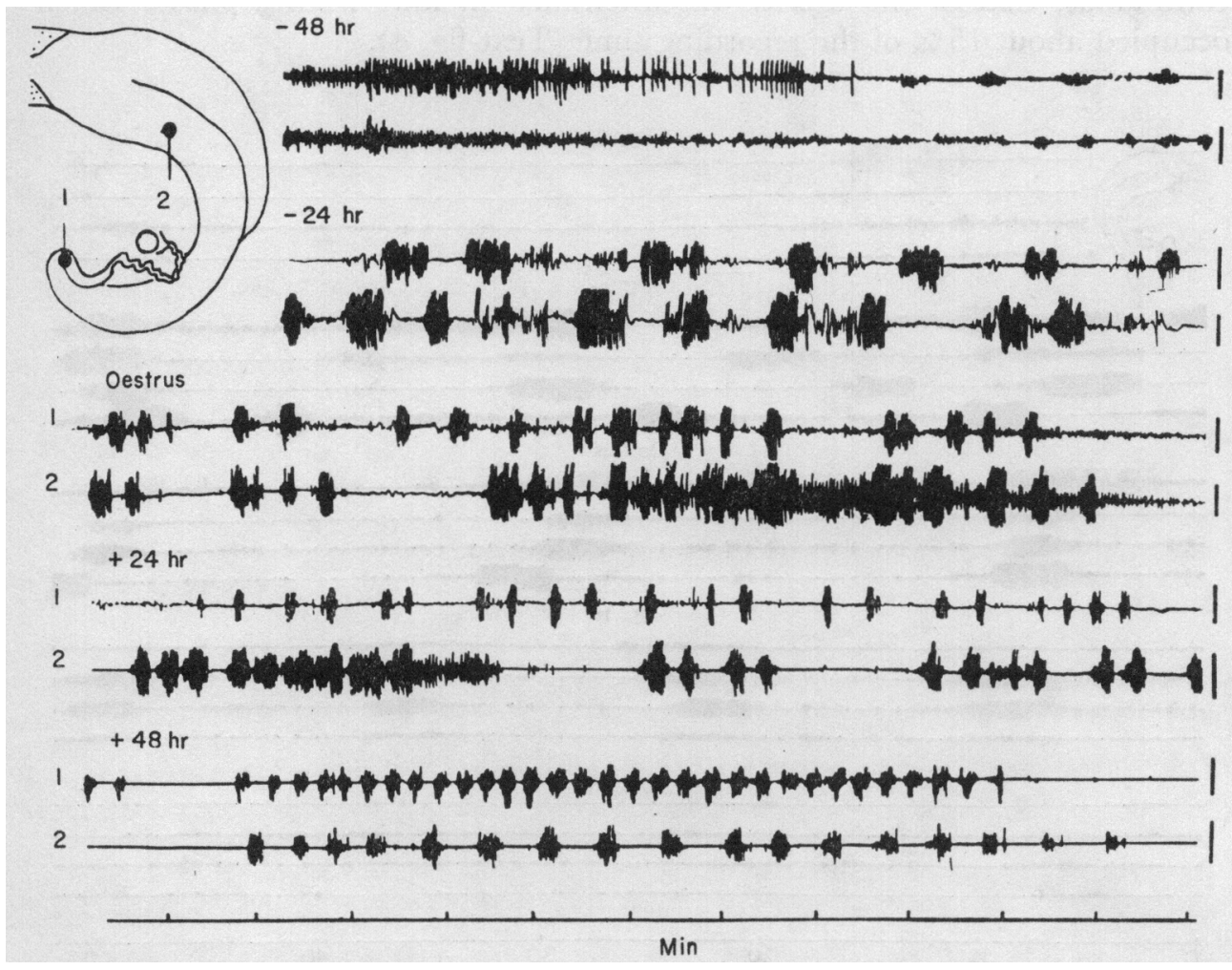

TEXT-FIG. 2. The normal patterns of uterine activity in the cow. A typical train of potentials is shown at the tubal end (1) $48 \mathrm{hr}$ before oestrus. Bursts of activity are manifest $24 \mathrm{hr}$ before oestrus at both tubal and cervical (2) regions. At oestrus, the cervical end shows a phase (trains and bursts) of activity lasting $5 \mathrm{~min}$. Only bursts are seen at late metoestrus ( $+48 \mathrm{hr}$ ). Calibration: $500 \mu \mathrm{V}$.

(a)

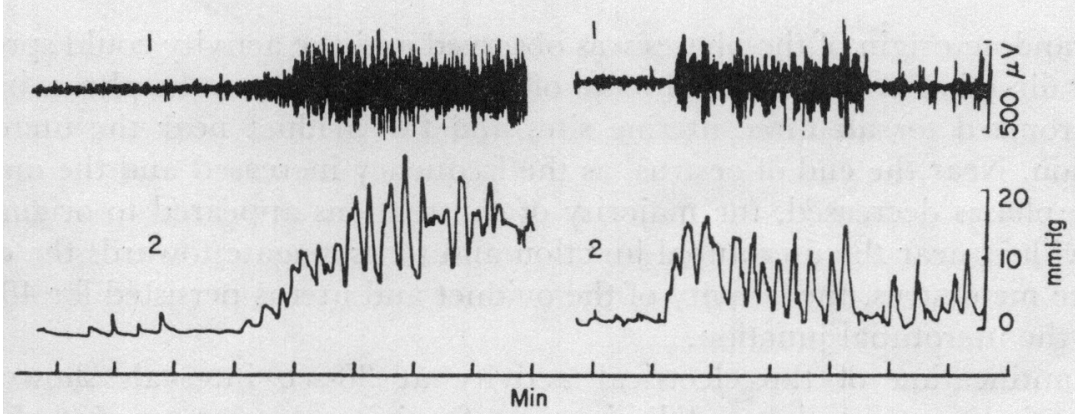

TEXT-FIG. 3. The uterine electrical activity (1) and pressure changes (2) in the cow. The mean level of pressure is increased when trains of potentials predominate (a). More isolated pressure responses occurred during a phase with bursts (b). 


\section{Temporal organization of activity}

Electromyograms condensed by high speed replay from a magnetic tape showed that the activity related to the onset of oestrus commenced by trains of potentials at the uterotubal junction. When the activity of the oviduct became continuous, that of the uterus was intensified in long lasting phases which occupied about $15 \%$ of the recording time (Text-fig. 4).

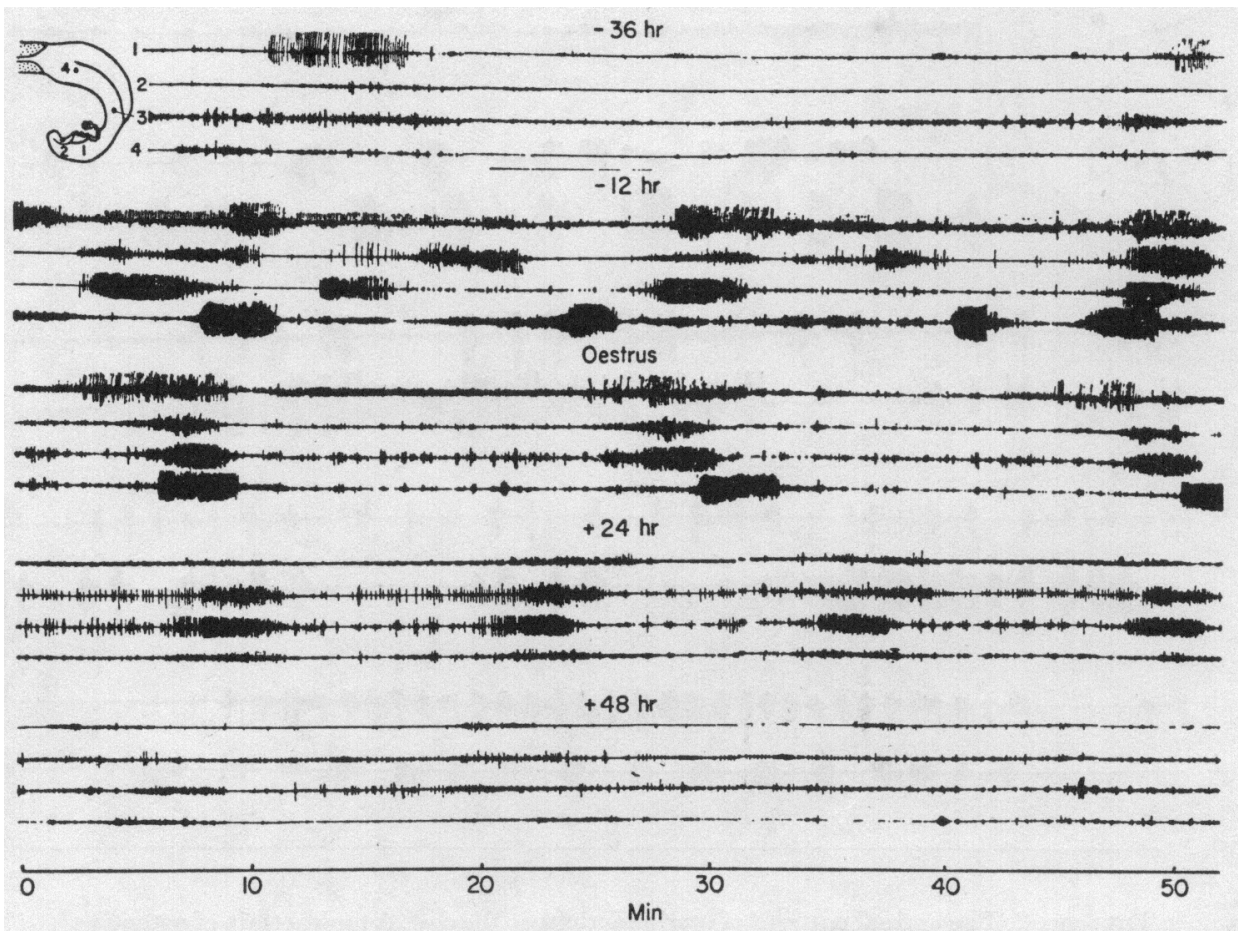

TExr-FIG. 4. The relationship between the activity of the oviduct (1) and the uterus (2, 3 , 4 ) at oestrus in the cow. Trains of potentials are visible on the oviduct at $-36 \mathrm{hr}$. Phases develop on the uterus at the onset of oestrus. Synchronization has taken place at oestrus. By $24 \mathrm{hr}$ after oestrus, the phases are less intense and more frequent. Low activity persisted into late metoestrus $(+48 \mathrm{hr})$.

A random origin of the phases was observed and the activity could spread in either direction until the actual onset of oestrus. Thereafter, the phases became synchronized for all three uterine sites and the oviduct near the uterotubal junction. Near the end of oestrus, as the frequency increased and the duration of the phases decreased, the majority of contractions appeared to originate in the oviduct near the uterotubal junction and to propagate towards the cervix. At late metoestrus, the activity of the oviduct and uterus persisted for 48 to 72 $\mathrm{hr}$ at the uterotubal junction.

Quantification of the electrical activity at 30-sec intervals showed the progressive augmentation and diminution of activity covering a period of 5 days for the uterine horn. For $72 \mathrm{hr}$ of this period, the activity occurred every 1 to 5 min in short phases. During the $24 \mathrm{hr}$ corresponding to oestrus, the integrated 
recording registered a tendency to rhythmic fusion of the previously short phases into prolonged phases of activity every 20 to $30 \mathrm{~min}$ (see Text-fig. 5 before injection of oxytocin).
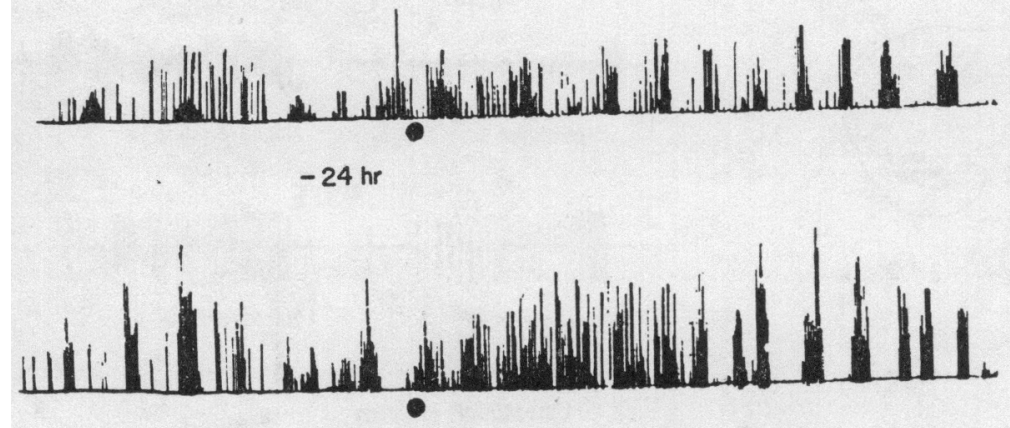

$-12 \mathrm{hr}$

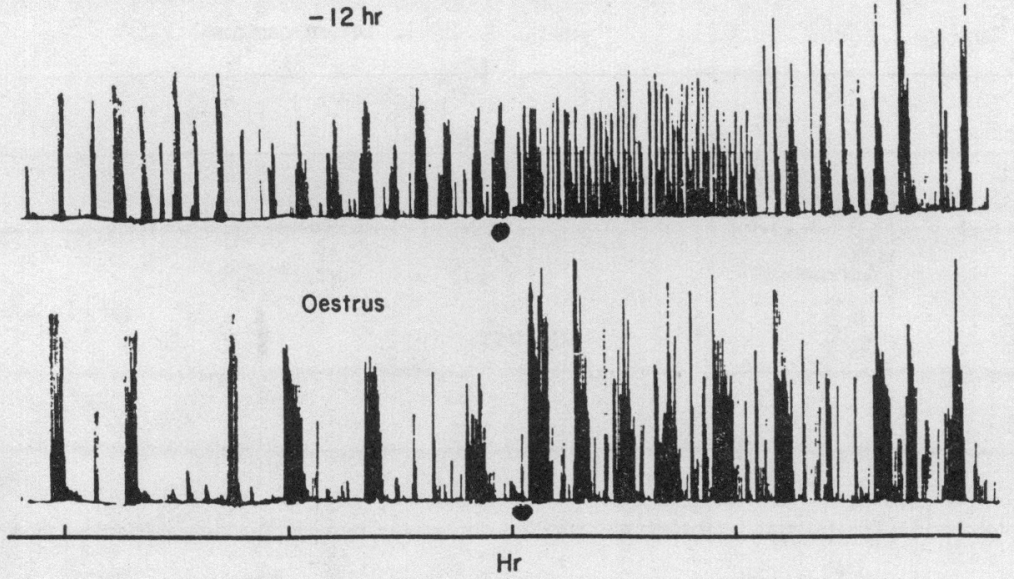

TEXT-FIG. 5. The integrated records of uterine activity (corpus uteri) and the effects of oxytocin in the cow. The short phases seen 24 and $12 \mathrm{hr}$ before oestrus are progressively replaced by prolonged phases of activity during oestrus. Their strength and number are doubled over a period of 60 to $90 \mathrm{~min}$ following injection of oxytocin, indicated by a spot (O).

\section{Effects of oxytocin, catecholamines and vaginal stimulation}

Oxytocin at the concentration used only had an effect during the period of oestrus and its action was only seen at the tubal end of the uterus: when administered 2 days before or after oestrus, the response occurred 30 to $50 \mathrm{sec}$ after the injection and consisted of an increased number of bursts for an 80-min period. When administered at oestrus, the latency was reduced to $10 \mathrm{sec}$ and the response involved both the uterus and the lower part of the oviduct. The frequency of the prolonged rhythmic phases of activity was doubled for about $2 \mathrm{hr}$.

At oestrus, the effect of adrenaline on the oviduct was inhibitory while that of noradrenaline was excitatory. Both catecholamines induced a brief motor 
response (bursts followed by a train of potentials) by the uterus, intense and prolonged in the case of noradrenaline, followed by a marked inhibition lasting 2 to 4 min especially after adrenaline. The tubal end of the uterus was the most sensitive to these effects (Text-fig. 6).

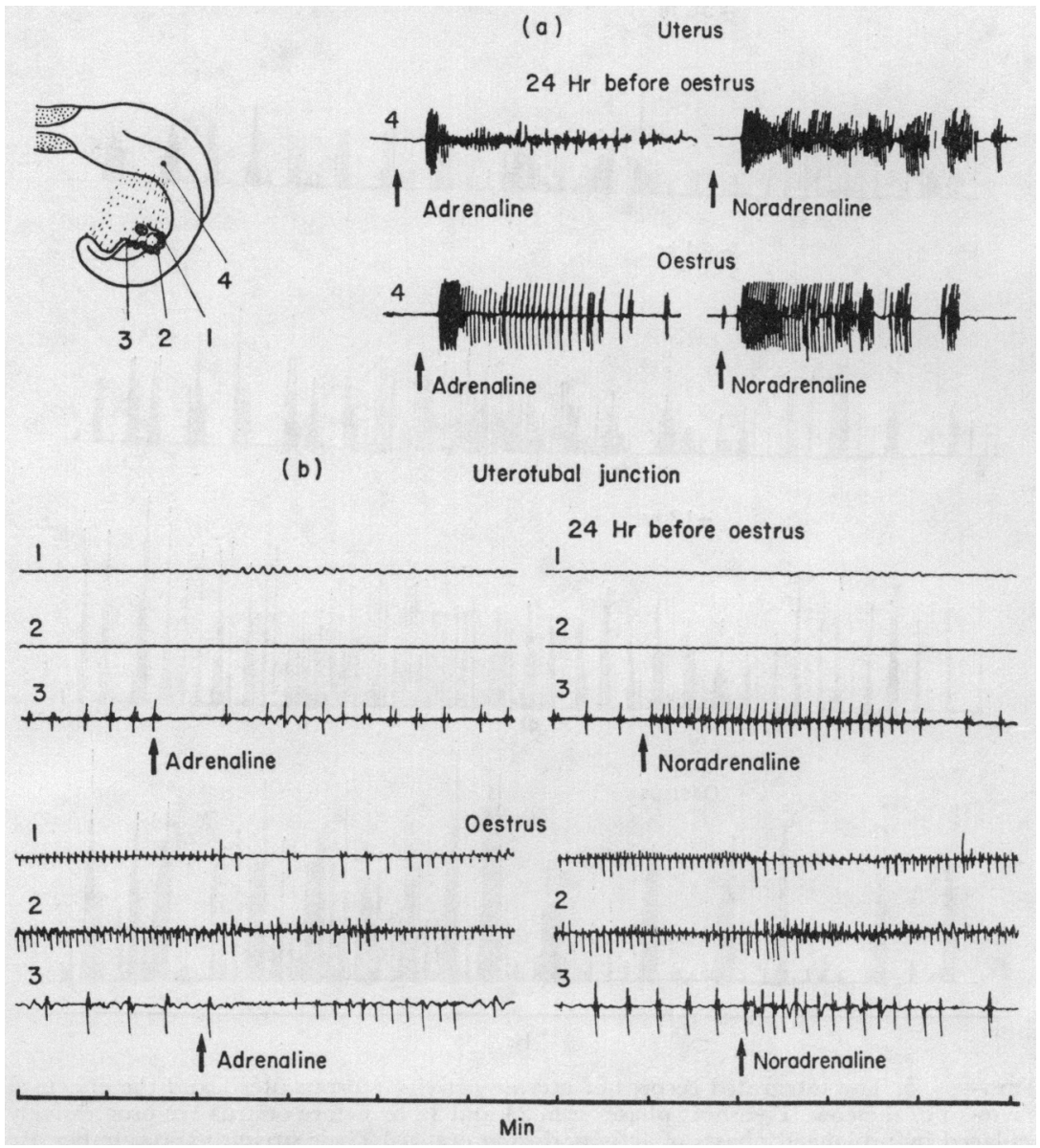

TEXT-FIg. 6. The uterotubal sensitivity to catecholamines at the onset of oestrus in the cow. (a) Uterus. An increased motor response, which is less marked for adrenaline than for noradrenaline, precedes relaxation and becomes more pronounced during oestrus (4). (b) Oviduct and uterotubal junction. The effects of adrenaline (inhibitory) and of noradrenaline (excitatory) increase as oestrus approaches.

An intense and continuous motor response similar to the phases of maximal amplitude was observed on the lower part of uterus at the oestrous period during a 20-sec vaginal stimulation. The response was prolonged over the whole of the uterus and the lower part of the oviduct from 5 to $30 \mathrm{~min}$ beyond the time of stimulation at actual oestrus.

In the ovariectomized Cow $U$, the activity resembled that seen from Days 6 to 18 of the cycle, and injection of oestrogen induced within 18 to $20 \mathrm{hr}$ a pattern of activity typical of that seen at the uterotubal junction during oestrus in Cow C. The prolonged and synchronized phases of activity usually seen only 
at oestrus were observed over a period of 5 days. The effects of both catecholamines and vaginal stimulation were likewise prolonged.

\section{DISCUSSION}

As far as we know, with the exception of recordings on the cervix (Chen et al., 1966), the activity of the oviduct or uterus has not previously been studied by electromyography in the cow. The technique used here seems to avoid many abnormal reactions of the myometrium as demonstrated by a fully quiescent uterus during dioestrus and absence of any shortening of the three cycles examined. In Cow $M$, in which a small balloon was placed into the uterus at oestrus for 4 weeks, bursts of activity persisted during dioestrus and oestrus occurred earlier (18 days). Concomitant measurements of the progesterone blood level served as an indication of the normal hormonal environment. No changes in the progesterone level were observed following surgery, or after giving small doses of oxytocin; this differs from the modifications seen after injection of large doses of oxytocin (Armstrong \& Hansel, 1959). Considerations of preovulatory and post-oestrous peaks of oestradiol-17 $\beta$ were not taken into account due to the limits of sensitivity $(10 \mathrm{pg} / \mathrm{ml})$ of the method used. We were unable to detect oestradiol- $17 \beta$ in the jugular venous plasma at a level higher than $10 \mathrm{pg} / \mathrm{ml}$ or to correlate it with the pattern of activity. These findings are more in agreement with the data reported by Glencross et al. (1973) and Dobson \& Dean (1974) than with those of Shemesh, Ayalon \& Lindner (1972) or Mason, Kristnamurti \& Kitts (1972).

It is of interest to note that the oviduct displayed only one kind of activity, i.e. trains of potentials. This may be due to the simpler organization of its muscle layer. The fact that different changes in uterine tone and pressure occurred during trains of potentials and bursts, respectively, may indicate a separate response from the outer and inner layers of the myometrium. If so, the prolonged phase would correspond to sustained contractions of the whole myometrium.

Considering the activity of the two portions of the genital tract examined, the points of interest are (i) the precocious activity of the lower part of the oviduct and the continuation of uterotubal junction activity into dioestrus, and (ii) the development of the uterine activity into synchronized phases during oestrus. Evidence that the uterotubal junction acts as the primum movens of the activity at the oestrous period is provided by the observation of a similar phenomenon induced in the quiescent nature of the ovariectomized cow after injection of oestradiol benzoate. The persisting activity of the uterotubal junction into dioestrus could be related to egg migration. The fact that the activity becomes progressively synchronized over the uterus and lower part of the oviduct at oestrus and also originates from the uterotubal junction is ascertained when oxytocin is given. Oxytocin usually increased the frequency and amplitude of the phases at oestrus without any changes in their origin. Thus, the activity of the oviduct and the upper segment of the uterus during the oestrous cycle as well as the sensitivity to drugs known to affect uterine contractility support the concept that the uterotubal junction is of paramount importance in the regulation of uterine activity. 


\section{ACKNOWLEDGMENTS}

This work was in part supported by Ministère de l'Agriculture (D.G.E.E.R.). We are most grateful to Mrs M. Ruckebusch (C.N.R.S.) for blood sample analysis and to Mr L. Bueno (I.N.R.A.) for surgery. Dr R. N. B. Kay and Dr M. Phillippo kindly read the manuscript. Mr J. P. Serthelon gave valuable technical assistance.

\section{REFERENCES}

Armstrong, D. T. \& Hansed, W. (1959) Alteration of the bovine oestrous cycle with oxytocin. F. Dairy Sci. 42, 533-536.

Chen, T. W., MacDonald, M. A. \& Hawes, R. O. (1966) Mechanical and electrical activities of the female bovine genital tract in vivo. Can. F. anim. Sci. 46, 25-29.

Dobson, H. \& DeAN, P. D. G. (1974) Radioimmunoassay of oestrone, oestradiol-1 $7 \alpha$ and 17- $\beta$ in bovine plasma during the oestrous cycle and last stages of pregnancy. 7. Endocr. 61, 479-486.

DöckE, F. (1962) Untersuchungen zur Uteruskontraktilität beim Rind. Arch. exp. VetMed. 16, 12051209.

Evans, E. \& Mrller, F. W. (1936) Uterine motility in the cow. Am. F. Physiol, 116, 44-45.

Glencross, R. G., Munro, I. B., SENIOR, B. E. \& Pope, G. S. (1973) Concentrations of oestradiol-17 $\beta$, oestrone and progesterone in jugular venous plasma of cows during the oestrous cycle and in early pregnancy. Acta endocr., Copenh. 73, 374-384.

Hays, R. L. \& VAnDemark, N. L. (1953a) Spontaneous motility of the bovine uterus. Am. F. Physiol. 172, 553-556.

Hays, R. L. \& VANDEmaRk, N. L. (1953b) Effects of oxytocin and epinephrine on uterine motility in the bovine. Am. F. Physiol. 172, 557-560.

LAtour, A. (1973) Un dispositif simple d'analyse quantitative de l'électromyogramme intestinal chronique. Annls Rech. vétér. 4, 347-353.

Mason, B. D., Kristnamurti, G. R. \& KITTS, W. D. (1972) Oestrone and oestradiol in jugular vein plasma during the oestrous cycle of the cow. $\mathcal{F}$. Endocr. 55, 141-156.

RuckeBtisch, Y. (1970) The electrical activity of the digestive tract of the sheep as an indication of the mechanical events in various regions. F. Physiol., Lond. 210, 857-882.

Ruckebusch, Y. \& GRIVEL, M. L. (1974) A technique for long-term studies of the electrical activity of the gut in the foetus and neonate. In Proc. 4th Int. Symp. on Gastro-Intestinal Motility, p. 428-434. Ed. E. E. Daniel. Mitchell Press, Vancouver.

Shemesh, M., Ayalon, N. \& LindNer, H. R. (1972) Oestradiol levels in the peripheral blood of cows during the oestrous cycle. F. Endocr. 55, 73-78. 